\title{
Effect of $\alpha$-tocopherol as a green inhibitor on chloride-induced corrosion of steel
}

\author{
Regina Fuchs-Godec ${ }^{1, *}$, Milorad V. Tomić2 ${ }^{2}$ Miomir G. Pavlović2 \\ ${ }^{1}$ Faculty of Chemistry and Chemical Engineering, University of Maribor, Smetanova 17, Slovenia, \\ ${ }^{2}$ University of Eastern Sarajevo, Faculty of Technology Zvornik, Karakaj b.b., Republic of Srpska \\ *E-mail: regina.fuchs@um.si
}

doi: $10.20964 / 2019.08 .158$

Received: 23 April 2019 / Accepted: 25 June 2019 / Published: 7 October 2019

\begin{abstract}
Immersion of stainless-steel (SS) samples of type X4Cr13 in ethanol solutions of stearic acid, with and without addition of $\alpha$-tocopherol, resulted in a modified surface with hydrophobic and corrosion resistance characteristics. We observed a double effect: a hydrophobic and corrosion-resistant surface of SS type $\mathrm{X} 4 \mathrm{Cr} 13$ in a solution of $3.0 \%$ (wt.) $\mathrm{NaCl}$ at $25^{\circ} \mathrm{C}$.

The corrosion properties of bare and modified surfaces of stainless steel were tested by polarization and electrochemical impedance spectroscopy (EIS) in $3.0 \%$ (wt.) $\mathrm{NaCl}$ solution at $25^{\circ} \mathrm{C}$. To observe the morphology and microstructures of sample surfaces, a Scanning Electron Microscope (SEM) was used after the electrochemical measurements. The results obtained from potentiodynamic polarisation measurements show that the inhibition effectiveness of $\mathrm{X} 4 \mathrm{Cr} 13$ reached $\approx 68 \%$ in cases when surfaces were modified in stearic acid alone (EIS measurements $\approx 82 \%$ ), while the values increased to more than $99.0 \%$ (for both methods) with addition of $\alpha$-tocopherol (E307). Modification of the surface using an immersion method in an ethanol solution of stearic acid, especially with addition of $\alpha$ tocopherol, appears to be a promising treatment for improving the corrosion resistance of stainless steel (SS) X4Cr13.
\end{abstract}

Keywords: green inhibitor, steel, high-level-hydrophobic layer, fat soluble vitamin, aggressive media

\section{FULL TEXT}

(C) 2019 The Authors. Published by ESG (www.electrochemsci.org). This article is an open access article distributed under the terms and conditions of the Creative Commons Attribution license (http://creativecommons.org/licenses/by/4.0/). 